\section{Las técnicas constructivas en la formación de al-Andalus}

Rafael Azuar Ruiz

Director Técnico del Museo Arqueológico Provincial de Alicante

\begin{abstract}
Resumen
El estudio de las técnicas constructivas en la formación de al-Andalus se enmarca dentro del debate sobre el paso de la Antigüedad Tardía a la Alta Edad Media y desde el análisis de los procesos que intervienen en la producción arquitectónica. A lo largo de los siglos VIII y Ix, se observa las dificultadas en la recuperación y normalización de la demanda arquitectónica, en donde conviven los proyectos edilicios en sillería concertada con los construidos en tapial. Esta dualidad en las técnicas constructivas es un ejemplo de la lenta y difícil islamización de la península que culminó en el siglo x con el califato Omeya de Córdoba y que supuso el desarrollo de un verdadero programa arquitectónico andalusí.
\end{abstract}

Palabras clave: Al-Andalus, sillería concertada, tapial, Alta Edad Media

\begin{abstract}
The study of the constructive techniques in the formation of Al-Andalus is framed inside the debate about the transition from the late antiquity to the high Middle Ages and from the analysis of the processes that participate in the architectural production. Along the VIII and IX centuries, it is observed the difficulties in the recovery and standardization of the architectural demand where the projects of buildings in arranged masonry cohabit with the ones built in «tapial» (walls of compressed mud). This duality in the constructive techniques is an example of the slow and difficult the Islam formation progress of the peninsula that culminated in the $x$ century with the Umayyad caliphate of Cordoba and that it supposed the development of a real constructive programme of Al-Andalus.
\end{abstract}

Key words: Al-Andalus, arranged masonry, tapial, High Middle Ages
Dentro de la V Semana de Estudios Medievales celebrada en la localidad riojana de Nájera, organizada por los Amigos de la Historia Najerillense», del 1 al 5 de Agosto de 1994, impartí una conferencia sobre: "Las técnicas constructivas en al-Andalus. El origen de la sillería y el hormigón de tapial», publicada al año siguiente (AZUAR: 1995) en la que planteaba, en primer lugar la ruptura que supuso la conquista frente a las tesis tradicionales de la continuidad tecnológica y en segundo lugar, la necesidad de integrar la normalización de los procesos tecnológicos en los primeros siglos del Islam en la península dentro de la dialéctica de formación del estado Omeya en al-Andalus.

La oportunidad que se me brinda al invitarme a participar en esta publicación, me permite revisar aquel planteamiento inicial desde una perspectiva totalmente diferente, marcada por el debate abierto por Luis Caballero Zoreda, dentro del más general sobre el paso de la Antigüedad Tardía a la Alta Edad Media, de la necesidad de conocer las claves de la arquitectura y el arte islámico y su influencia determinante en la conformación de las manifestaciones artísticas cristianas producidas durante los primeros siglos de la conquista islámica de al-Andalus. Debate planteado hace algunos años y cuyas fases y claves ya fueron descritas por el mismo L. Caballero (2000), así como discutidas en la reunión celebrada en Mérida en 1999, sobre: «Visigodos y omeyas. Un debate entre la antigüedad tardía y la Alta Edad Media». En la complejidad y matices del mismo, el análisis de las técnicas constructivas y de los procesos de trabajo prácticamente suponen una cuestión colateral o de poco interés, explicable dentro del modelo general constructivo y, la mayoría de las veces, relegado al ámbito de la continuidad tecnológica: "(de la mampostería a la sillería), sin plantearse que los aparejos pudieron ser coetáneos, acomodados a las caracteristicas de materiales y tradiciones técnicas" (CABALLERO 2000: 210).

La tradicional tesis «evolucionista» del conocimiento tecnológico, junto al planteamiento opuesto de la «simultaneidad» de los aparejos en los edificios de la alta edad media, prácticamente han vaciado de interés su investigación y quizás ello explique la falta de estudios en esta línea, sobresaliendo, por su excepcionalidad, la investigación y las hipótesis planteadas por J. Antonio Quirós (2001), el cuál —siguiendo lo constatado en Italia en cuanto a la reutilización generalizada de la sillería y su interpretación dentro del proceso productivo de la arquitectura en la alta edad media-, describía así las transformaciones experimentadas en el paso de la antigüedad tardía a la edad media que supusieron la "desarticulación del sistema de explotación de las canteras y de otras estructuras productivas — como los hornos de ladrillos y tejas_, lo que generó en algunas ocasiones un comercio de mate- 
riales reutilizados, aunque tuvo una perduración limitada. (...) todo ello provocó la unificación de los artesanos en pocas categorías (...) El cantero como tal desapareció y también el lapicida o picapedrero, por lo que el ciclo productivo de la piedra se limitó solamente a dos fases (obtención del material reutilizado o perecedero y colocación en la obra) propias del arte de la albañilería $y$ de la carpintería» (QUIRÓs 2001: 281-2).

Esta falta de especialización en la mano de obra y la reducción en las fases de la producción edilicia, facilitó la movilidad de los artesanos y la aparición por consiguiente de grupos de artesanos itinerantes que se desplazaban de una a otra construcción. De alguna manera, estos grupos serían los transmisores de los conocimientos tecnológicos y conformarían la cuarta y última condición definida por L. Caballero (2000: 216-7) y necesaria para que se diera la transmisión de los conocimientos de lo islámico a lo cristiano.

La pretendida aparición de estos grupos en los primeros años de la conquista de al-Andalus, con claros conocimientos decorativos orientales, como única explicación de la construcción de los edificios palatinos del Plá de Nadal (Ribarroja, Valencia) y el que supuestamente existe en Torre-La Cruz (Villajoyosa, Alicante) (CABALlero 1994-5; 1998; 2000) ya fue contestado desde el punto de vista de la cronología arqueológica y estratigráfica de los yacimientos (GUTIÉRREZ 2000) y desde el análisis de la formación del califato de Córdoba por M. Acién (2000). Por lo que la aparición de estos grupos de artesanos con conocimientos tecnológicos hay que seguramente vincularla al desarrollo de los programas edilicios islámicos construidos con sillería, y si fuera así habría que explicar cuál es su contexto, ya que según J. A. Quirós (2001: 289) «La aparición de la sillería supone una compleja organización del trabajo de la arquitectura $y$ por tanto es necesario explicar cual es el contexto socio-económico que favorece la demanda de arquitectura de "prestigio"

Desde estas premisas de análisis, planteo esta revisión de mi primer trabajo en la que pretendo poner de manifiesto la intrínseca relación existente entre el conocimiento tecnológico y la dialéctica de la formación y consolidación de la sociedad islámica de al-Andalus.

\section{LA CONQUISTA ISLÁMICA Y LA DESARTICULACIÓN DEL PROCESO CONSTRUCTIVO}

Todos los estudiosos de la arquitectura de al-Andalus, desde los clásicos M. Gómez Moreno (1951), L. Torres Balbás (1987), hasta los más recientes debidos a F. Valdés (1988) o a M. Barrucand y A. Bednorz (1992), etc. coinciden en que, lamentablemente, de los primeros edificios islámicos documentados por las fuentes de la conquista en la península - como fueron la mezquita sevillana de la Robina, en donde fue asesinado en el año 716-7 el hijo de Musa b. Nusayr, las mezquitas de Madînat Ilbîra y de Granada levantadas por Hanas b. 'Abd Allâh al-San'anî, muerto en el año 719, o de la mezquita de Algeciras mandada levantar por 'Abd alRahman I en el año 755 (VALdÉs 1988: 549)—, se desconocen como eran ya que no se ha conservado vestigio material alguno de los mismos.

A este desconocimiento de cómo fueron las primeras mezquitas hay que añadir la falta de datos disponibles sobre los primeros edificios civiles, toda vez que, como se ha visto anteriormente, se ha desechado el posible reaprovechamiento islámico de los edificios tardoantiguos de la TorreLa Cruz de Villajoyosa o del Plá de Nadal, incluído por J. Zozaya en su reciente investigación sobre las «Fortificaciones tempranas en Al-Andalus dentro del grupo de edificios considerados como de la fase "pre-andalusín o documentados entre el 711 y el 756 (ZoZAYA 2002: 54).

De estos años hasta la construcción de la mezquita de Córdoba por 'Abd al-Rahman I en el 786-7, primer edificio del que tenemos datos constructivos, sólo conocemos la famosa noticia de la reconstrucción del puente de Córdoba, acometida por el gobernador Al-Samh en los años 719-720, para lo que necesitó la autorización directa del califa de Oriente, según la «Ajbar Machmuâ» traducida por E. Lafuente (1867: 35):

"(...) Si el Emir de los creyentes me ordena que reconstruya el muro de la ciudad, asi lo haré, pues para ello tengo medios con lo que sobra de los impuestos después de pagar al Chund, y de proveer á la guerra santa; pero si el Emir lo prefiere, con la piedra de este muro reconstruiré el puente. Dícese que Omar le mandó levantar el puente con la piedra del muro, y reparar éste con ladrillo si no se encontraba piedra. Puso Aç-Çamh manos a la obra y reconstruyó el puente en el año 101»

La noticia de la reconstrucción de este puente ya fue comentada en su día por L. Torres Balbás (1987: 339), y le sirvió de ejemplo para valorar el desconocimiento que tenían los conquistadores de la ubicación de las tradicionales canteras y su incapacidad para labrar la sillería, ya que se veían obligados a utilizar en las reconstrucciones ladrillos y adobes. Para comprobar las deducciones extraídas del texto es necesario recurrir a la información tecnológica que nos aportan las recientes excavaciones de los niveles emirales en las antiguas ciudades de la Hispania romano-visigoda. Así, en la publicación de los hallazgos de época emiral documentados en la ciudad de Mérida, en el área arqueológica de Moreria, dados a conocer en una primera información por P. Mateos y M. Alba (2000) y, posteriormente, ampliados por este último (AlBa 2001), es de gran interés el gran conjunto compuesto por los nueve edificios construidos 
con anterioridad a la construcción de la alcazaba, no sobre los restos de edificaciones anteriores, sino sobre los espacios libres sin edificar de la ciudad visigoda y que constituyen, "el mayor conjunto de arquitectura emiral documentado hasta el presente en la península» (MATEOS, AlBA 2000: 158) De estos edificios y siguiendo las características del edificio «A», el mejor conservado, sabemos que está construido con mampostería rematada por tapial y poseía cubierta de teja plana «muy alejada del patrón romano» (MATEOs, AlbA 2000: 158). De los rasgos del conjunto, M. Alba nos aporta una descripción más detallada: «sorprende la diversidad de sistemas constructivos empleados, con aparejos heredados del mundo romano, como las cimentaciones de cantos de río, el opus africanum, o el incertum reforzado por sillares en la intersección de los muros y para el enmarque de los vanos. Por lo general, en alzado, los zócalos de mampostería sustentan muros de tierra que opcionalmente pueden ir enfoscados con argamasa. Para la unión de la mampostería se usa la tierra, a veces minima, casi en seco, y en menor medida cal (...) Todo el material es reutilizado, procedente de expolios, sillares, cornisas, tambores, etc, y los materiales más diversos que conforman el incertum, desde la piedra corriente a fragmentos de mármol, de ladrillo, pizarra (para los calzos), etc (...) no asi en las techumbres donde si bien se utiliza tegula, ésta es de formato más pequeño, de escaso grosor y moldura estrecha con poco resalte» (AlBA 2001: 289-90).

Los rasgos constructivos de estos edificios son de por sí elocuentes: muros con zócalos de mampostería, con refuerzos de sillería reutilizada en las esquinas y levantados en barro, y edificios con cubiertas de tejas de tamaño más reducido que las romanas. Todo ello confirma lo descrito sucintamente por los textos: reaprovechamiento de la sillería e introducción en la construcción de tejas y de adobes, producidos expresamente, con los que quizás levantarían los muros, considerados de barro.

Similar comportamiento en la producción arquitectónica del primer siglo de la conquista se atestigua en el Tolmo de Minateda (Hellín, Albacete), en donde se ha documentado como una vez que el gran bastión que defendía el ingreso a la ciudad visigoda — atribuible posiblemente a época bizantina-, quedó destruido parcialmente con la conquista islámica, no se reconstruyó posteriormente sino que se abandonó y sobre una cota más retrasada se levantó "un agger o albarrada de tierra y piedras sobre el sector más elevado del baluarte» (GUTIÉRREZ, ABAD 2002: 140). Esta pobre intervención defensiva se acompaña de una nueva trama de viviendas y usos industriales sobre los restos de la basílica de la parte superior en la que se reemplea mucho material de expolio para levantar unos muros, de apariencia muy similar al de las viviendas de época visigoda, de ci- mentación de mampostería trabada con barro que soportan paredes de tierra, y que se cubrían en algunas ocasiones con tejas curvas (ABAD, GuTiÉrREZ, SANZ 1998: 107). Siendo frecuente el hallar entre los muros, como mampuestos, ajimeces y fragmentos de canceles de la basílica (GUTIÉRREZ 2000: 111-2).

Rasgos técnicos muy similares se han documentado en las excavaciones de los niveles emirales de la segunda mitad del siglo VIII de la antigua ciudad de Volúbilis en Marruecos. Así, las estructuras de viviendas halladas al norte de la domus de Compas y que suponen una clara compartimentación de la vivienda romana, así como su cambio de uso, presentan los siguientes rasgos constructivos (AKERRAZ 1998: 301) "Ces pièces sont toutes construites en moellons disposés en paraments et liés à la terre; des blocs de remploi sont utilisés aux angles et en chaînages. Aucune trace de l'utilisation de briques crues ou de terre en élévation des murs n'a été remarquée».

Los documentos arqueológicos coinciden en definir, para el primer siglo de la conquista, una intervención constructiva islámica caracterizada por unos edificios que se levantan en mampostería trabada con mortero de barro, utilizando en sus aparejos algunos sillares procedentes del expolio de los edificios anteriores, los cuales se utilizan para reforzar las esquinas y las puertas, como se ha documentado en las excavaciones de Cercadilla (Hidalgo, FuerTes, 2001: 248) y en otros barrios emirales de la ciudad de Córdoba (Murillo, Casal, Castro, 2004); en conjunto, no se documentan labores de talla de cantería o de preparación de sillares, sólo labores de aparejar muros, los cuales se rematan o levantan en tapiales o adobes de barro, cubriéndose en algunos casos con tejas, de nuevo diseño como aportación original de los nuevos pobladores.

La dinámica observada en el proceso constructivo y constatada arqueológicamente no sólo en la península, sino también en el norte de África, en el primer siglo de la conquista, es que la construcción está marcada por la ausencia de canteros o maestros especializados en la extracción y talla de la piedra; así como se ha constatado la inexistencia de edificios de aparejos concertados, sino todo lo contrario: la arqueología nos sitúa ante la realidad de una arquitectura de mampuestos, reaprovechamiento de sillares y muros de barro, etc. Rasgos de una producción arquitectónica y edilicia que contrasta con la construcción del único edificio conservado, de los mencionados por las fuentes, levantado en este primer siglo: nos referimos a la mezquita de Córdoba mandada edificar por 'Abd Al-Rahman I entre los años 786-787, de la que se conocen un importante número de estudios (GÓmEz Moreno 1951; TORREs BALBÁs 1987; JimÉNEZ 1979; VALdÉs 1985; BARRUCAND, BEDNORZ 1992), gracias a los cuales sabemos que para su construcción 
se recurrió al expolio de columnas y capiteles, aunque su colocación fue el resultado de una detenida y consciente labor de selección y ubicación de los mismos según un predeterminado programa decorativo-religioso (CRESSIER 1984-5). Sus muros se cimientan sobre sillares en seco sobre mampostería, y gracias a las recientes excavaciones llevadas a cabo en lo que fue la fachada oriental de la mezquita — que excavara F. Hernández en los años treinta (MARFIL, 1999:175)—, se ha podido comprobar que el muro de cierre era «de sillería a soga y tizón, enlucido y pintado con despiece de falsa sillería, (...) andén ataluzado entre contrafuertes, con núcleo de cal y canto y zócalo de sillerías (MARFIL 2000:137).

El análisis arqueológico del edificio pone de relieve la originalidad del conjunto, no sólo arquitectónica y decorativamente, sino constructivamente, ya que es la primera vez en la que se documenta —en una obra eminentemente islámica construida en la península en el siglo VIII-, un desarrollo concebido en sillería desde sus cimientos, para los que también por primera vez se utiliza como trabazón el mortero de cal. Aspectos éstos que ponen de relieve la complejidad y diversidad de esta producción edilicia que obliga a contar con trabajadores especializados en el retallado de columnas, basas y capiteles expoliados, apertura de canteras, traslado y acarreo de piedras, normalización de la talla de sillería en formas y medidas determinadas; es decir, no se aparejan sillares de diversas medidas en disposición concertada. A todo ello hay que añadir las aperturas de caleras y tejares u hornos para la cocción de ladrillos para soportar las presiones de los arcos, etc. En conclusión, el análisis de los datos constructivos de este edificio nos define una complejidad en su proceso edilicio que indiscutiblemente no tiene nada que ver con lo que está sucediendo en el resto de la península y que sólo se puede justificar y explicar desde la directa intervención del Estado a la hora de concebir y ejecutar un proyecto constructivo de esta categoría.

Indiscutiblemente, si la arqueología no nos engaña a la hora de interpretar los restos constructivos del muro oriental de la primigenia mezquita, ya que desconocemos en qué indicadores cronológicos se basó P. Marfil para considerarlos como del siglo VIII, pues los también arqueólogos cordobeses M.a del Camino Fuertes y Rafael Hidalgo, excavadores de Cercadilla, han puesto de relieve la dificultad de diferenciar las producciones cerámicas islámicas del siglo VIII en la ciudad de Córdoba (2003: 518). A ello, hay que añadir lo sorprendente del perfecto aparejo de la sillería de los contrafuertes, dispuesta a soga y tizón en un módulo de sillares de aproximadamente $1,20 \mathrm{~m}$. de largo por $0,60 \mathrm{~m}$. de alto y $0,40 \mathrm{~m}$. de ancho, dimensiones éstas prácticamente similares a los aparejos posteriores de época califal (AZUAR, 1995) y a los que podríamos considerarlos como su precedente. Perfec- ta técnica de aparejo de sillares de nueva talla que contrasta, inexplicablemente, con la dominante construcción aérea, caracterizada por la reutilización y reempleo de sillares labrados de época romana o visigoda (CRESSIER, 1984-5; 2001). Todas éstas cuestiones nos sitúan ante la duda de sí estos restos excavados corresponden exactamente a la primera mezquita cordobesa o más bien son el fruto de refracciones posteriores?

La respuesta no la conocemos y menos aún dudamos de la seriedad científica de las investigaciones de nuestro colega y amigo Pedro Marfil; pero hay que reconocer el que - como se recoge en las actas del II Simposio de Arqueología celebrado en Mérida en 2001 sobre las «Cerámicas tardorromanas y altomedievales de la Peninsula Ibérica: ruptura $y$ continuidad» (CABAllero, Mateos, Retuerce, 2003)—, todavía hoy resulta muy difícil, por falta de datos objetivos ceramológicos, el identificar con claridad los contextos arqueológicos de los primeros decenios de la conquista de alAndalus. Por ello, seguimos considerando las informaciones arqueológicas que conocemos de la primitiva mezquita de 'Abd al-Rahman I, aunque su fábrica y aparejo nos sitúan ante un hito singular y sin continuidad en el proceso constructivo de la primera época emiral —opinión ésta compartida por Pedro Gurriarán que ha estudiado las técnicas constructivas andalusíes hasta el califato (2004: 300)—. En fin, edificio singular ya que, según las fuentes, se levantó en un solo año? y se destinaron 180000 dinares, de los cuales 100000 se pagaron a la comunidad cristiana por la compra del solar y el resto se destinaron a la ejecución de la obra (TORRES BALBÁS 1987: 345; VALDÉS 1988: 550). Obra monumental de la que seguimos desconociendo los prototipos que la inspiraron, ni quién o quienes fueron los arquitectos, ni de donde procedían los artesanos que la construyeron, en un Al-Andalus del siglo VIII que construía sus escasos edificios con muros de barro sobre zócalos de mampostería, con refuerzos de sillería reutilizada..., como así sucedió en el año 793 cuando el emir Hixam I construyó dos pequeñas mezquitas frente al alcázar de Córdoba con los materiales traídos, como botín de guerra, desde Narbona (ACIÉN, VALLejo 1998: 115).

\section{LA FORMACIÓN DE UNA INCIPIENTE ARQUITECTURA DEL EMIRATO}

La complejidad y desarrollo del proceso constructivo de la primitiva mezquita de Córdoba se puede equiparar al amplio programa edilicio que desarrolló 'Abd al-Rahman II, sesenta años después y vinculado a la necesidad de consolidar el Emirato Independiente. El mejor ejemplo material de esta política es indiscutiblemente la misma ciudad de Córdoba (MARFIL 2000) en donde, como han analizado M. Acién y A. Vallejo, el Emir llevó a cabo un intenso pro- 
grama constructivo destinado a dotar a la ciudad de las bases administrativas del Estado y que comenzamos a conocer arqueológicamente — según el reciente avance dado a conocer por Juan F. Murillo, María Teresa Casal y Elena Castro de la Gerencia Municipal de Urbanismo de Córdoba (2004)—. Así, 'Abd al-Rahman II fundó la Dâr al-Sikka y el Tirâz, remodeló el alcázar, amplió la mezquita y favoreció el asentamiento de nuevos pobladores con la construcción de diversas mezquitas que generaron arrabales en el sector occidental (ACIÉN, VALLEJo 1998: 117ss) De todas estas intervenciones, lamentablemente, apenas han quedado restos, a la vez que generan ciertas dudas: así, todavía se está discutiendo cuál es el espacio de la nueva intervención efectuada en la mezquita, respecto al perfectamente definido de época de 'Abd Al-Rahman I, de cuya ampliación sólo se conocen 11 capiteles, aunque se sabe que ya se comienzan a tallar, y de la reforma de la puerta de San Esteban no hay dudas por la inscripción que la ejecutó Muhammad I, su sucesor (VALDÉS 1988: 561-3). Es decir, para analizar los rasgos tecnológicos de las construcciones de 'Abd al-Rahman II hay que acudir a sus obras levantadas fuera de la capital.
La alcazaba de Mérida es, de todas ellas sin discusión, la más importante, ordenada construir en el año 835, para sede del gobernador y de las tropas, con el fin de defender a la población musulmana de las continuas agresiones promovidas por las disputas entre muladíes y beréberes de la zona. Es un gran recinto fortificado de planta cuadrangular de $132 \mathrm{~m}$. por $137 \mathrm{~m}$., con cubos macizos en saliente y en su ingreso en recto se encontraba la lápida de su fundación, en la que consta fue dirigida su obra por el liberto Yayfar b. Mukassir. De su construcción y sus precedentes se han ocupado diversos autores (GÓMEZ MORENO 1951: 45-6; TORRES BALBÁS 1987: 379-386; VALDÉS 1988: 561-569; BARRUCAND, BEDNORZ 1992: 46-7) por lo que remitimos a su consulta. Sin embargo, es interesante resaltar que, técnicamente, para su fábrica se emplearon «fundamentalmente sillares de factura romana dispuestos sin ordenamiento rítmico a soga y tizón con relleno interior de cascotes envueltos en argamasa. Toda la fábrica es de material reutilizado procedente del expolio como cantera de las defensas erigidas en el siglo $V$, (...) de las áreas funerarias paganas y de numerosos edificios públicos ya en desuso» (AlBA 2001: 283). De similares rasgos

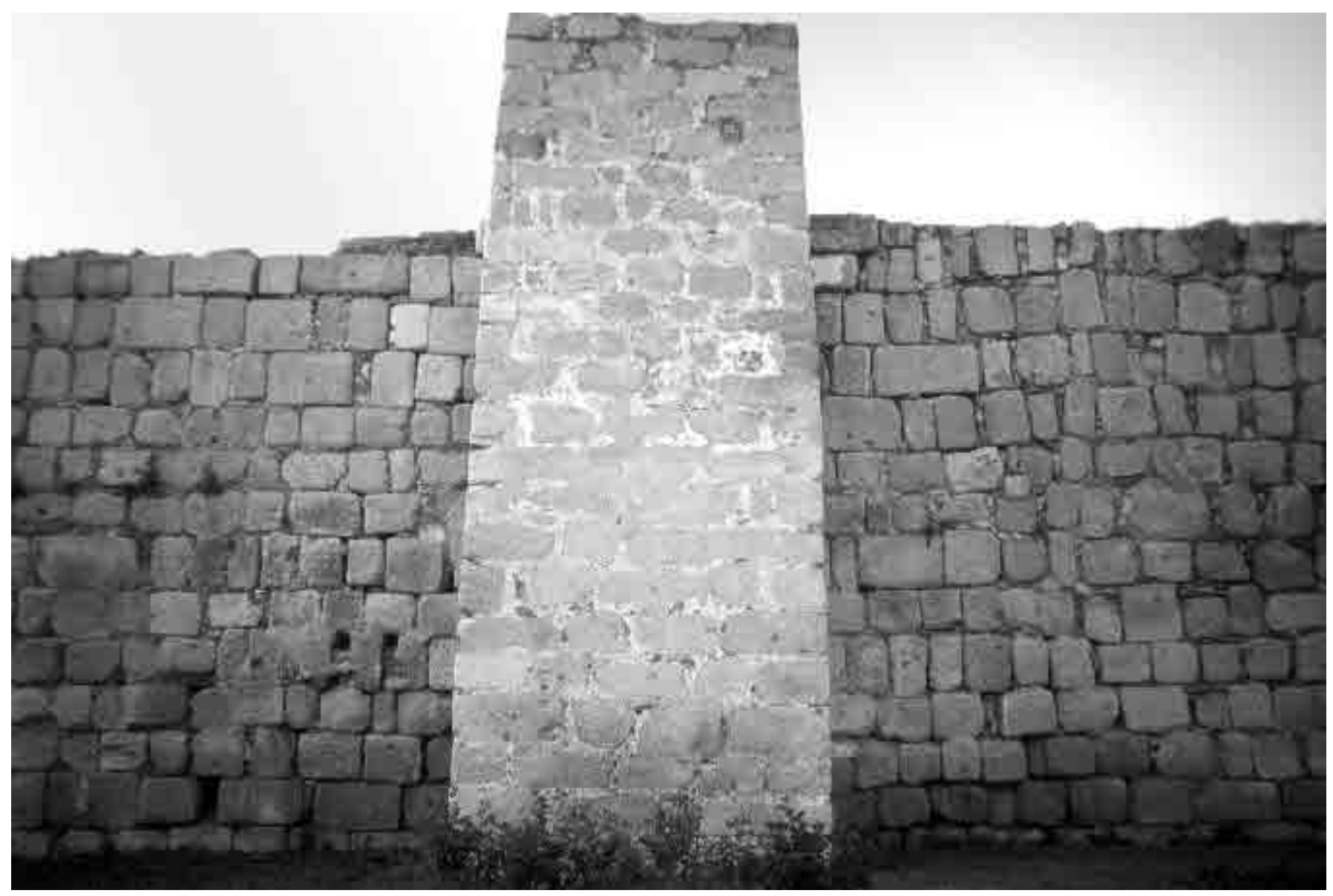

Detalle del muro de la entrada a la alcazaba de Mérida 
constructivos es el aljibe levantado en su interior y estudiado en su día por F. Valdés (1995).

El primer recinto del alcázar de Sevilla presenta unas características formales y de planta muy parecidas al alcázar de Mérida (TABALES 2002), ya que su planta es rectangular con cubos en saliente y está realizado todo él en sillería reaprovechada, concertada en irregulares y dispersas series de «soga y tizón». La obra está considerada como de época califal (JIMÉNEZ 1979: 481), pero coincidiendo con M. Valor Piechota (1991;1992), las indudables similitudes con la alcazaba de Mérida, en cuanto a planta, materiales y aparejos nos lleva a defender la cronología de Ibn al-Qutiya que relata como después de la incursión normanda sufrida por la ciudad de Sevilla, 'Abd Al-Rahman II mandó en el año 844/5 su construcción con piedras de la mejor calidad y se encargó dicha tarea al sirio Abdala Ben Sinan (VAldés 1988: 561)

Este incipiente programa de construcciones para consolidar y favorecer el control emiral de los distritos se vio ampliamente desarrollado por el sucesor Muhammad I, al que todas las fuentes escritas y epigráficas (SOUTO 2002) coinciden en atribuirle la fundación y consolidación de las ciudades de Talamanca del Jarama, Madrid y Huesca, así como refortificó Calatayud, Daroca, etc. (MAZzoli-GuinTARD 1998: 102). Por suerte, de la mayoría de estas fundaciones tenemos datos arqueológicos que nos permiten conocer sus rasgos constructivos. Así, de las murallas de Madrid levantadas en el año 852 (ZoZAYA 1990: 198), junto a Talamanca del Jarama, Medinaceli, etc., se han conservado restos de su primer recinto en la zona de la cuesta de la Vega, cerca del antiguo alcázar y debajo del actual emplazamiento del Palacio Real. Las excavaciones y estudios llevados a cabo sobre su trazado y sus características técnicas, nos ponen de manifiesto que eran de sillería de sílex en su cimentación y de caliza en su parte posterior, dispuesta a la manera califal en soga y tizón (CABALLERO et alii 1983: 40).

Las excavaciones llevadas a cabo en la ciudad de Huesca a finales de la década de los años ochenta, sacaron a la luz un tramo de más de sesenta metros de la antigua muralla islámica de Huesca (ESCO, SÉNAC 1987), constatándose que toda ella estaba realizada en sillería, dispuesta mayormente a tizón, de 0,40 por 0,40 , en la parte exterior. Esta muralla corresponde a la fortificación llevada a cabo por el gobernador Amrus Ibn Umar en el año 874/5, por encargo del Emir Muhammad I para defender la frontera superior (ESCO, GirALT, SÉNAC 1988: 27-28).

De características constructivas muy similares son los restos de la alcazaba de Balaguer, en el actual Castell Formós que se erige sobre la ciudad, de la que se conservan varios paños de lo que debió ser la primitiva alcazaba emiral. Fue Ch. Ewert (1979) quien en su detallado estudio nos aporta los primeros datos sobre la fortificación emiral que debe corresponder al lienzo norte, por donde se accede hoy al castillo, compuesto por tres cubos en saliente, cuya zarpa está realizada en sillería a tizón y las hiladas superiores a «soga y tizón» (Esco, Giralt, Sénac 1988: 20ss). Este frente disponía de dos torres albarranas, de las mismas características, pero desaparecidas hoy en día. Sabemos por el texto de Ibn Hayyan que la alcazaba fue construida en época del Emir 'Abd Allah por Lubb b. Muhammad en el año 897/8 (Giralt 1986).

Por último, de características constructivas muy similares son los castillos de Piracés y de algunos otros de Huesca, que corresponden a la tipología de las fortificaciones de altura o «husun», junto con otros como el de la Iglesieta (Usón, Huesca) o el de Alberuela de Tubo (Huesca), estudiados por C. Escó y Ph. Sènac $(1987 a$; 1991) y considerados como sincrónicos a las fortificaciones de Huesca y Balaguer, es decir de la segunda mitad del siglo IX, por sus evidentes paralelos: están construidos en sillería dispuesta, generalmente, a tizón, de 0,40 por 0,40 m., y todos ellos muestran una documentación arqueológica de la época y, por tanto, podrían encuadrarse dentro de la política de fortificaciones llevadas a cabo por el Estado, en la segunda mitad del siglo IX, para defender la frontera superior.

En resumen, un siglo IX marcado por una gran actividad constructiva, fruto del desarrollo de un ambicioso programa edilicio desarrollado por los emires, primero por 'Abd al-Rahman II que consolidó a Córdoba como sede político-administrativa del incipiente estado omeya, y posteriormente por su hijo Muhammad I que extendió el programa iniciado por su padre a los territorios fronterizos de al-Andalus. En las obras conservadas se observan idénticos rasgos constructivos ya que son obras realizadas en sillería concertada, apreciándose una evolución tecnológica importante: en las más antiguas es dominante la presencia de sillares reutilizados procedentes de expolio, como sucede en los casos de Mérida y Sevilla, mientras que en las de cronología más moderna, como serían las construcciones de la frontera superior, es patente la normalización de la sillería, con dominio absoluto del sillar modular, siendo el caso más elocuente el de la muralla de Huesca, lo que es un claro ejemplo de la presencia de canteros y picapedreros y, por tanto, asistiríamos a los inicios o fundamentos del desarrollo de un incipiente mercado constructivo que demandaría un desarrollo de la especialización en los oficios, así como el de la apertura de canteras, caleras y tejeras, y por supuesto de la organización de los circuitos o redes de distribución de los materiales constructivos. Proceso que, en general, es bastante desigual lo que reafirma el estado incipiente de la producción y el mercado de la construcción, a la vista 


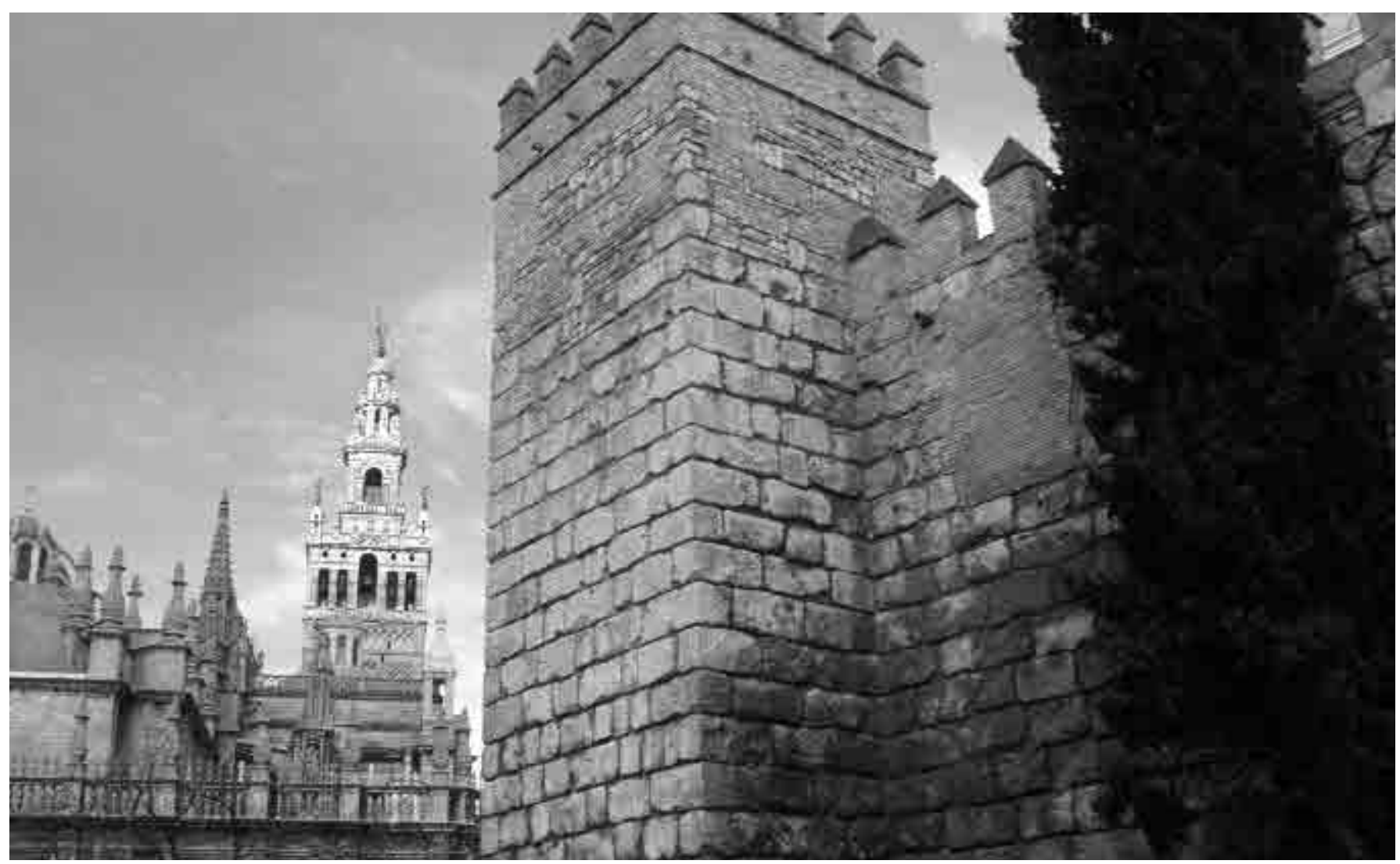

Restos de la alcazaba emiral de Sevilla

de los resultados obtenidos por Pedro Gurriarán en su reciente análisis técnico-constructivo de las fortificaciones levantadas por el emirato en al-Andalus (2004).

La normalización documentada en las técnicas y en los aparejos de sillería a partir del gobierno de 'Abd al-Rahman II, sólo se puede explicar desde su encardinación en un programa de mayor desarrollo y con claros objetivos. $\mathrm{Y}$ en este sentido, es fundamental para su comprensión el detenerse en los aspectos estructurales o formales de las construcciones, en las que se observa la presencia de las zarpas ataulatadas en la base de las torres, como se observa en la alcazaba de Mérida o en la de Balaguer, y que según S. Martínez Lillo tendrían su origen en las soluciones arquitectónicas, con escasos ejemplos en la península (MARTíNEZ 1991: 18ss) y muy abundantes en el norte de Africa (PrIngle 1981). El origen Bizantino de estas soluciones y, por ende, de las construcciones emirales vendría reforzado por otro rasgo fundamental: la planta de las alcazabas. Ciertamente la marcada influencia bizantina de las plantas cuadrangulares de estas primeras alcazabas ya fue puesta de manifiesto por L. Torres Balbás (1987), por A. Jiménez (1979) y por autores posteriores como F. Valdés (1988), J. Zozaya $(1984,1992)$ y M. Barrucand (1992).
Si analizamos las informaciones que disponemos sobre la construcción de estas obras, sabemos que los alcázares de Mérida y de Sevilla fueron levantados bajo el gobierno de 'Abd Al-Rahman II, soberano que introdujo un modelo administrativo de corte 'abbasí (ACIÉN, VALLEjo 1998: 117) y por ello no resulta difícil explicarnos que, según menciona Ibn Al-Qutiyya, la alcazaba de Sevilla fuera encargada su realización al sirio 'Abd Allah Ibn Sinan (JimÉNEZ 1979; VALOR 1991: 89ss). Desconocemos la procedencia del liberto Yayfar b. Mukassir al que se le encargó los trabajos de la alcazaba de Mérida (VALdés 1988: 559), o la de los eunucos Nasr y Masrur encargados de la ampliación de la mezquita de Córdoba llevada a cabo en el año 848 y de la reforma de la puerta de San Esteban de los años 855/6 (VALDÉs 1988: 561ss), pero es indudable que nos encontramos ante constructores islámicos y seguramente, traídos del Medio Oriente. La procedencia del constructor del alcázar sevillano, viene a confirmar la fuerte influencia siria de las construcciones del Emirato, como ya señalara K.A.C. Creswell al hablar de la mezquita de Córdoba (1979: 333-4) y, por tanto, no resulta incomprensible señalar como modelos de estas fortificaciones cuadrangulares del Emirato, los castillos Omeyas de la primera época: Qsar al-Hair, Msatta, Qsar at-Tuba, etc. (CRESWELl 1979). 


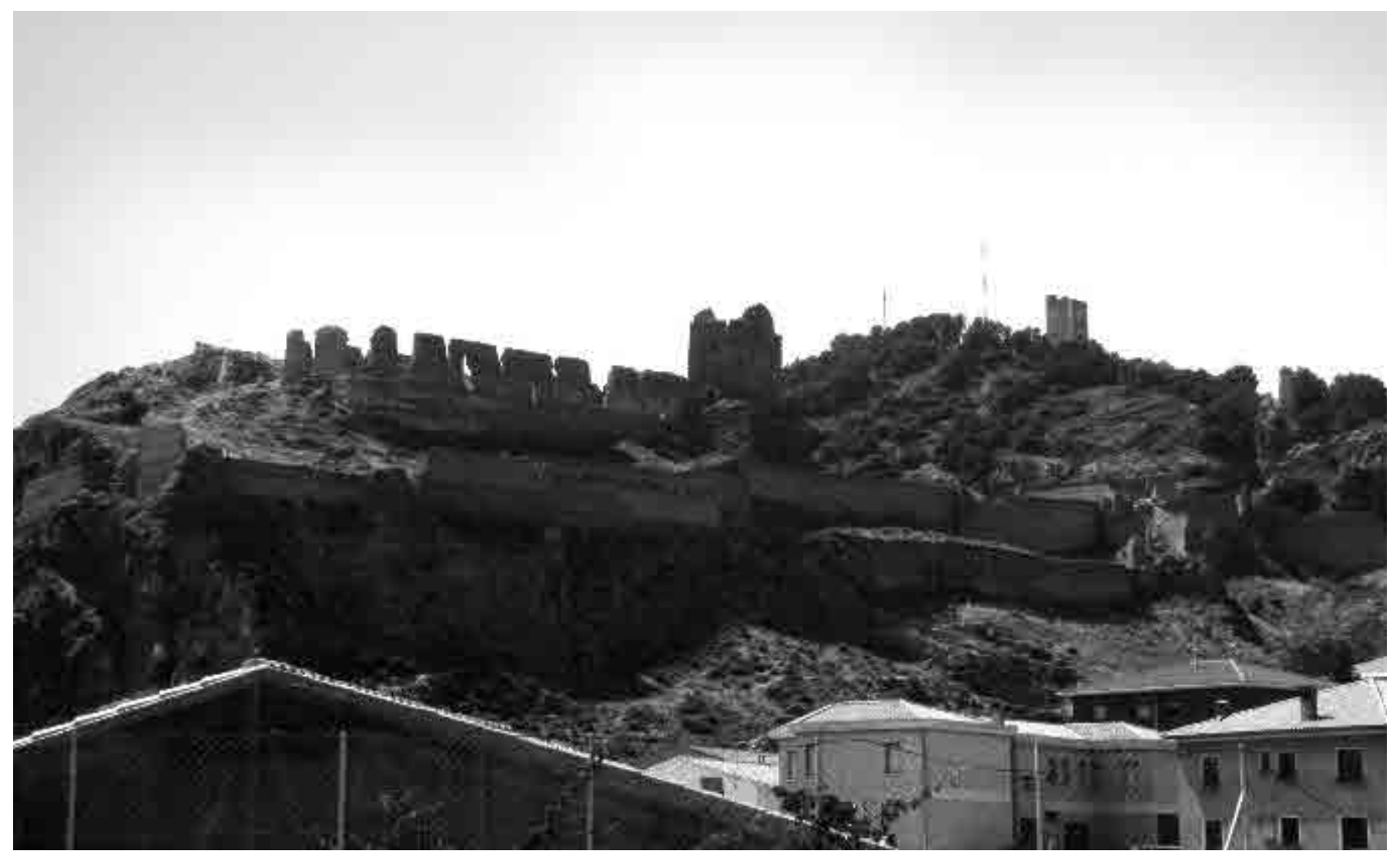

Detalle del recinto superior de Daroca, realizado en tapial

Aparte de estas cuestiones de precedentes formales arquitectónicos, nos parece más interesante la concepción y utilización de este modelo cuadrangular de construcciones defensivas para levantar o implantar la nueva administración del Estado, creando estos espacios para acoger la residencia del gobernador y de las tropas, emplazadas en los pasos de los grandes ríos y vinculados a la mezquita que se levanta fuera del alcázar, pero dentro de un complejo político-administrativo o "Dar al-Imara» (JimÉNEZ 1979: 481-3), que constituiría el espacio de representación del Estado, caracterizado por su construcción en sillería concertada, a imitación de la política de control y fortificación desarrollada por el Islam a lo largo del siglo VIII para consolidar sus fronteras, como serían un claro ejemplo las fortificaciones levantadas por los Aglabíes en la actual Túnez, los cuales también desarrollaron plantas rectangulares en sillería, muy similares a las andalusíes (LEZINE 1966).

\section{LA ARQUITECTURA DE LA DISIDENCIA. EL HORMIGÓN DE TAPIAL FRENTE A LA SILLERÍA}

La cantidad e importancia de las construcciones de sillería encargadas o levantadas directamente por el Emirato independiente no constituyen el panorama general de la dinámica constructiva desarrollada en al-Andalus a lo largo del siglo IX, ya que a la par se documentan otros proyectos constructivos caracterizados no precisamente por la utilización de la sillería en su ejecución, sino por levantarse en fábrica de tapial.

La existencia de estas primeras cercas de tapial de tierra se constata arqueológicamente en el impresionante yacimiento del Plá d'Almatá de Balaguer, extensa fortificación de $27 \mathrm{Ha}$., con un frente amurallado conservado de $700 \mathrm{~m}$ en los que se alternan y documentan 24 torres en saliente. Prácticamente todo el recinto defensivo está levantado en tapial de barro, así como el interior de las torres que se elevan al exterior en sillería concertada, de módulo aproximado a 40 por $40 \mathrm{~cm}$. Según J. Giralt los tramos con las características descritas habría que datarlos a finales del siglo VIII, principios del siglo IX (GIRALT 1994: 240). El origen de esta extraordinaria fortificación es todavía un misterio, ya que sabemos que la fundación de la ciudad de Balaguer en el año 897 supuso un cambio importante en el antiguo asentamiento (GIRALT 1994: 223).

La arqueología todavía no ha resuelto la cronología concreta del yacimiento, pero sin embargo la similitud entre los módulos de sillería documentados en Piracés o en Huesca, como veíamos anteriormente y la conservada en el 


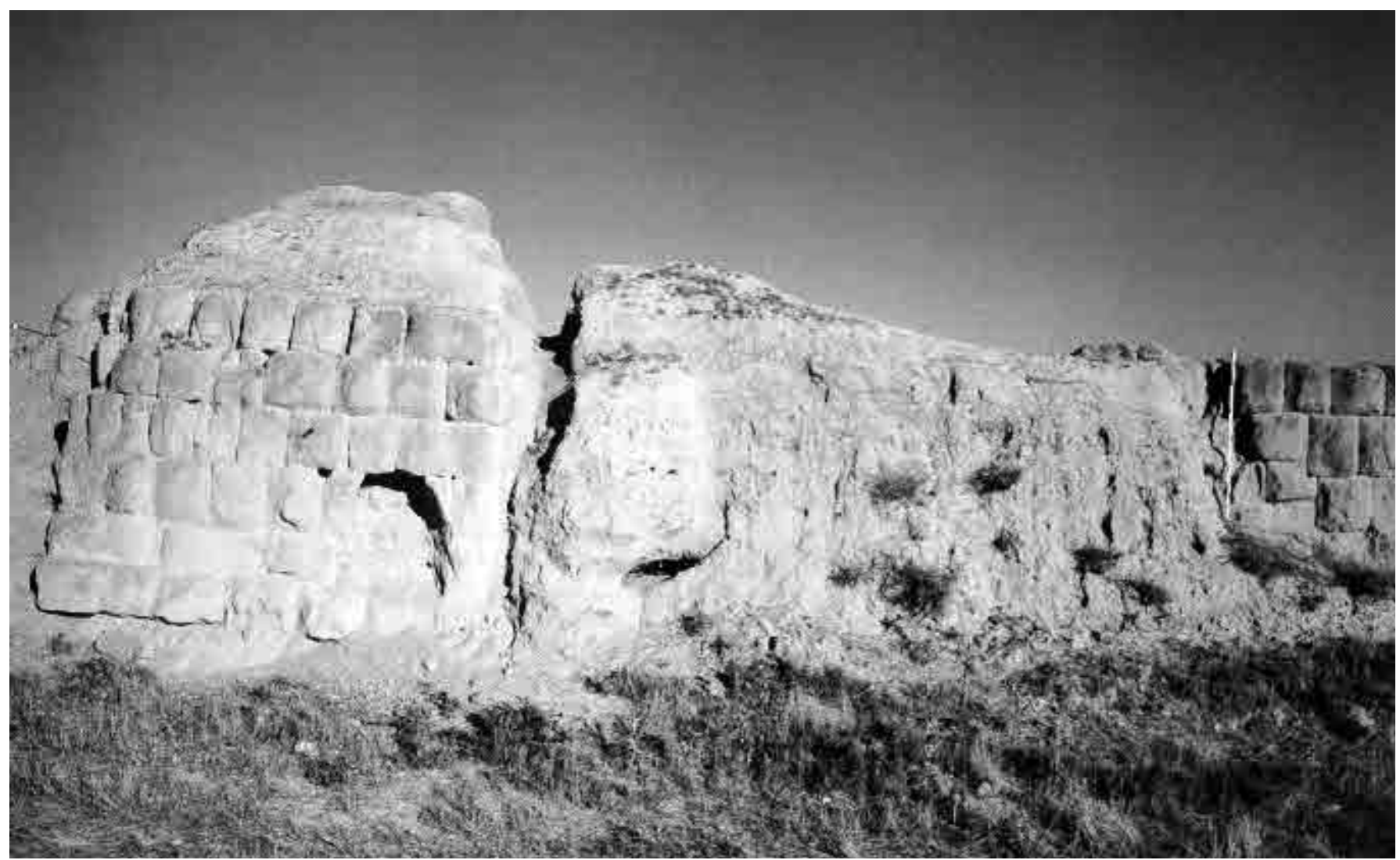

Detalle del lienzo de muralla del Plá d'Almatá (Balaguer), en donde se observa la fábrica de tapial y el refuerzo en sillería concertada (J. Giralt)

Plá d'Almatá me llevaron a sugerir su construcción, o por lo menos el refuerzo en sillería de las torres de tapial, como de los últimos años de Muhammad I y enmarcado dentro de la dinámica descrita (AZUAR 1995: 134).

En estos años y en este ambiente, se levantó la ciudad de Badajoz, fundada por el rebelde muladí 'Abd Al-Rahman b. Marwan al-Yilliqi (874-5), con permiso del Emir, el cual le proporcionó los albañiles y el dinero necesario para su construcción, según al-Bakrî y cuya noticia recogió siglos después Al-Himyarî (LÉVI-PROVENÇAL 1938: 58), de las traducciones al castellano (VALDÉs 2001: 347) reproducimos la siguiente (JIMÉNEZ, NAVARRO 2001: 84):

"El emir 'Abd Allâh autorizó la fundación y envió a 'Abd al-Rahmân un cierto número de albañiles y una suma de dinero: éste comenzó por construir la mezquita congregacional a base de ladrillo (labin) y tapial (tábiya) excepto el alminar que fue excepcionalmente construido en piedra. Se reservó una maqsûra en el interior de la mezquita y mandó construir otro oratorio particular en el interior de la ciudadela. También mandó edificar los baños que se hallan junto a la puerta de la villa. Conservó los albañiles a su disposición hasta levantar un cierto número de mezquitas. En su origen, las murallas de Badajoz estaban fabricadas con tapial de tierra (turâb)."
El texto no tiene desperdicio ya que nos describe con todo detalle como la fundación y construcción de la ciudad responde a un proyecto perfectamente definido en el que lo primero que se planifica es la construcción de los referentes de la ciudad islámica: las mezquitas, los baños, el alcázar y por último la muralla o cerca, toda ella en tapial, a diferencia de las anteriores construcciones emirales.

De aquellos primeros muros parece que no se han descubierto hasta el momento resto alguno (VALDÉs 1988). De la que sí quedan restos evidentes, es de la refortificación de Calatayud, debida a 'Abd Al-Rahman b. 'Abd al-'Aziz al Tuyibi, con permiso del emir Muhammad para controlar a los Banû Qasî, señores de la frontera, que se llevó a cabo en el año 884-5, junto a la fortificación de Daroca (VALDÉs 1988; Torres Balbás, 1987). Aunque, según J. A. Souto y siguiendo el texto de Al-'Udrî el origen de la refortificación habría que retrotrerla, dentro del gobierno de Muhammad I, a los años 862-3 (Souto 1989: 685). De esta fortificación disponemos de un importante estudio monográfico realizado por J. A. Souto que permite documentar, no sólo estas primeras obras en tapial sino también, la aparición novedosa en cronología tan temprana de torres albarranas (SOUTO 1983; 1990). 
Es interesante constatar como en la segunda mitad del siglo IX y con el fin de atajar o someter a los disidentes muladíes de las fronteras, el Emir Muhammad desarrolló un programa de alianzas con las familias pro-omeyas de los distritos, mediante el cual les ayudaba con medios económicos, técnicos y humanos, a fundar o refortificar ciudades, para cuya construcción se usó de forma general la técnica de la fábricas de tapial de tierra, de ejecución mucho más rápida y menos costosa que las fortalezas de sillería. Técnica que ya estaba generalizada no sólo en las construcciones urbanas, como vimos en los casos de Mérida, los arrabales emirales de Córdoba o en la ciudad de Pechina, fundada en el año 884-5 y en donde las paredes de las viviendas se levantaban en tapial de barro sobre zócalos de mampostería (ACIÉN et alii 1990; CASTILlo, MarTínez 1990).

\section{LAS TÉCNICAS CONSTRUCTIVAS EN LA FORMACIÓN DE AL-ANDALUS}

Las respuestas a las preguntas planteadas por Luis Caballero para explicar la arquitectura cristiana «visigótica», difícilmente creo que se encuentren en la arquitectura de los conquistadores musulmanes ya que, como se ha visto a lo largo del siglo VIII, se constata una profundización en la desarticulación de los diversos procesos de la construcción, en donde predomina el reaprovechamiento de materiales procedentes de expolio de los antiguos edificios, los cuales no se tallan sino que se aparejan en las esquinas o refuerzos de los edificios y en sus aberturas. Evidentemente, el reaprovechamiento de materiales nobles de épocas anteriores es también una cuestión de prestigio, como ya puso de manifiesto P. Cressier al estudiar los capiteles de la mezquita de Córdoba (CRESSIER 1984-5), y claro ejemplo de ello es el caso ya mencionado de la fundación de dos mezquitas en Córdoba por Al-Hakam I en el año 794 con materiales procedentes del botín de la campaña contra Narbona. El recurso de la utilización de materiales de expolio no se puede considerar por sí mismo un rasgo o característica definidora de la arquitectura de época emiral, ya que fue utilizado hasta por los almohades (CRESSIER 2001).

Por ello, hay que considerarlo como una manifestación más de un contexto en donde resulta evidente la desarticulación de los procesos de construcción, ya que se desconocían las canteras, los materiales se acopian, no hay constancia de la existencia de canteros, a la vista de que las técnicas utilizadas en la construcción son de aparejar mampuestos, predominantemente con argamasa de barro, sobretodo para levantar unos muros en fábrica de barro o de adobes, como mencionan las fuentes. Este panorama generalizado en el siglo VIII, tiene un hito o "unicum», sin antecedentes y sin continuidad, que sería la construcción de la mezquita de Córdoba por 'Abd al-Rahman I, obra que, contra el panorama general, es el primer ejemplo de la época construido totalmente en sillería, no sólo concertada sino normalizada, tallada modularmente y dispuesta de forma isódoma a «soga y tizón». Obra singular de alto costo, de la que las fuentes no aclaran como se puedo levantar en un solo año, en un ambiente sin tradición artesanal y sin infraestructuras documentadas necesarias para desarrollar cualquier programa constructivo.

Con posterioridad a esta inexplicable obra, desde el contexto tecnológico de la época, hay que esperar casi sesenta años para encontrarnos ante un verdadero programa o proyecto constructivo de amplio calado y que permite vislumbrar la incipiente normalización de los procesos y medios técnicos que necesita la construcción arquitectónica. Nos referimos al programa iniciado por el Emir independiente 'Abd al-Rahman II, el cual como medio para implantar la administración del incipiente estado omeya, lleva a efecto un programa político-militar basado en la construcción de centros administrativo-militares, las dar al-îma$r a$ o residencia de los gobernadores, desde donde se realizaba un mejor control administrativo-fiscal de las coras. Así, se construyen las alcazabas de Mérida y de Sevilla, cuyas plantas están inspiradas en precedentes bizantinos y sus rasgos constructivos son similares: se levantan en sillería concertada, procedente de expolio pero en donde ya se observa una organización en el acopio de materiales, los cuales se aparejan con argamasas de cal y es evidente la presencia cada vez mayor de canteros. Sabemos también que para desarrollar estos proyectos emirales se importan o encomiendan estas complejas defensas a maestros no precisamente andalusíes, sino orientales, como el conocido sirio 'Abd 'Allah Ibn Sînan al que se le encargó la construcción de la alcazaba sevillana.

Los modelos y diseñadores orientales de las obras estatales levantadas en esta época, confirman la inexistencia en al-Andalus de una tradición y de una infraestructura que permitiera el desarrollo de arquitecturas complejas de sillería. Igualmente, son proyectos desarrollados parcialmente o de forma incompleta ya que no van acompañados de un desarrollo decorativo, que por sí necesita de un importante número de artesanos muy preparado en la talla. Así, se comprende que como decoración en estos conjuntos sólo se conocen las famosas pilastras visigodas que adornan el templete que da acceso al aljibe de la alcazaba de Mérida (VALDÉs 1995), o los contados capiteles de la mezquita de Córdoba retallados imitando capiteles romanos. Es decir, la falta de este programa decorativo es fundamental para entender cuales son los perfiles, el calado y nivel de desarrollo del proceso constructivo alcanzado en el ecuador del si- 
glo IX, teniendo presente que todas las obras conocidas y estudiadas son obras construidas directamente por el Estado.

La dificultad de consolidar y desarrollar la producción arquitectónica comenzada por 'Abd al-Rahman II, se pone de manifiesto con el gobierno de su sucesor Muhammad I, el cual para apaciguar a los disidentes, sobretodo muladíes, de las coras desarrolló una política de pactos con aquellas familias de los distritos, marcadamente pro-omeyas, a las que ayuda con medios económicos, técnicos y humanos para que construyan sus ciudades, con todos sus elementos: mezquitas, baños, alcazaba, etc., recurriendo para ello a la utilización del recurso tecnológico del tapial para levantar sus muros, torres y edificios. Técnica ésta que no requiere acopio previo de materiales, ni poner en funcionamiento la compleja red de canteras, transporte, ni canteros especializados..., sólo es suficiente una caja realizada con simples tablones de madera, tierra, agua, algo de cal y mano de obra no especializada. Proceso tecnológico perfectamente conocido, cuya facilidad y reconocida rentabilidad económica hace que se siga utilizando hasta hoy en día.

La constatación documental y arqueológica de la coexistencia de estos dos procesos constructivos en las obras desarrolladas por el incipiente Estado Omeya, hasta finales del siglo IX, ponen de manifiesto una realidad en la que los complejos edilicios levantados en sillería no acaban de consolidarse y en donde sólo apreciamos la presencia de canteros especializados en aquellas obras de finales del siglo IX. Igualmente, resulta evidente la incapacidad del emirato para desarrollar un programa decorativo, lo que confirma el bajo y débil nivel de consolidación del proceso arquitectónico y constructivo. Todo ello, nos sitúa ante un panorama sólo explicable desde la compleja dinámica de la formación de al-Andalus, en la que la islamización de la sociedad sólo se consiguió bajo el califato y por ello, habrá que esperar al siglo X para que se consoliden todos los procesos constructivos de la arquitectura, con la formación de una demanda, el desarrollo de una especialización en el proceso productivo, de tal manera que permita la participación de una gran cantidad de artesanos (SOUTO 2001), y en el que, como opina M. Acién (2000: 440), adquiera un verdadero desarollo el programa decorativo, máxima expresión del consolidado Estado Omeya de Al-Andalus.

\section{Bibliografía}

AbAD, L.; GutiérRez, S.; SANZ, R., 1998, El Tolmo de Minateda. Una historia de tres mil quinientos años. Toledo.

ACIÉN, M., 2000, La herencia del protofeudalismo visigodo frente a la imposición del Estado islámico, Anejos a AespA, XXIII, 429-441.

ACIÉN et alii, 1990, Excavación de un barrio artesanal de Bayyana (Pechina, Almería), Archéologie Islamique, 1, 147-168.
ACIÉN, M., Vallejo, A.; 1998, Urbanismo y Estado islámico: de Córdoba a Qurtuba, Genèse de la ville islamique en al-Andalus et au Magreb occidental, (Madrid), 107-136.

AlBA, M., 2001, Mérida, entre la Tardoantigüedad y el Islam: datos documentados en el área arqueológica de Morería, Cuadernos Emeritenses, 17, 265-308.

AKERRAZ, A., 1998, Recherches sur les niveaux islamiques de Volubilis, en Genèse de la ville islamique en al-Andalus et au Magreb occidental, (Madrid), 295-304.

1867, Ajbar maymû’a. (ed. y trad. E. Lafuente y Alcántara), Madrid.

AZUAR, R., 1995, Las técnicas constructivas en Al-Andalus. El origen de la sillería y del hormigón de tapial, $V$ Semana de Estudios Medievales (Nájera), 125-142.

BARRUCAND, M.; BeDNORZ, A., 1992, Arquitectura islámica en Andalucía. Colonia.

CABAllero, L., et alii, 1983, Las murallas de Madrid. Excavaciones y estudios arqueológicos (1972 a 1982), Estudios de Prehistoria y Arqueologia Madrileñas, 1 (Madrid), 9-182.

Caballero, L., 1994-5, Un canal de transmisión de lo clásico en la alta Edad Media española. Arquitectura y escultura de influjo omeya en la península Ibérica entre mediados del siglo VIII e inicios del siglo X, Al-Qantara, XV-2, 321-384 y XVI-1, 109-124.

Caballero, L., 1998, Arquitectura visigótica y musulmana, ¿¿Continuidad, concurrencia o innovación?, Cuadernos Emeritenses, 15, (Mérida), 143-176.

CABAllero, L., 2000, La arquitectura denominada de época visigoda, ¿es realmente tardorromana o prerrománica?, Anejos a AespA, XXIII, 207-247.

Caballero, L.; Mateos, P. (editores), 2000, Visigodos y omeyas. Un debate entre la Antigüedad Tardía y la Alta Edad Media. Anejos a AespA, XXIII (Mérida-Madrid).

Caballero, L.; Mateos, P.; Retuerce, M. (editores), 2003, Cerámicas tardorromanas y altomedievales en la Península Ibérica: ruptura y continuidad. Anejos a AespA, XXVIII (Madrid).

CASTillo, F., MartínEZ, R., 1990, La vivienda hispanomusulmana en Bayyana-Pechina (Almería), La casa Hispano-musulmana, (Granada), 111-127.

Cressier, P., 1984-1985, Les chapiteaux de la Grande Mosquée de Cordoue (oratoires d'Abd al-Rahman I et d'Abd al-Rahman II) et la esculpture de chapiteaux à l'époque émirale, Madrider Mitteilungen, 25 (Madrid), 257-313; 216-281.

CREsSiER, P. 2001, El acarreo de obras antiguas en la arquitectura islámica de primera época, Cuadernos Emeritenses, 17, 309-334.

CRESWELl, K.A.C., 1979, Compendio de arquitectura paleoislámica. Sevilla (ed. y trad. A. Jiménez).

Esco, C.; Giralt, J.; SÉNaC, Ph., 1988, Arqueología Islámica en la Marca Superior de Al-Andalus. Huesca.

EsCo, C.; SÉnAC, Ph., 1987, La muralla islámica de Huesca, II Congreso de Arqueología Medieval Española, II, 589-601.

EsCO, C.; SÉNAC, Ph., 1987a, Un Hisn de la Marche Supérieure d'Al-Andalus: Piracés (Huesca). Melanges de la Casa Velazquez, XXIII, 125-150.

EsCO, C.; SÉNAC, Ph., 1991, Le peuplement musulmán dans le district de Huesca (s. VIII-XII siècles). La Marche Supérieure d'al-Andalus et l'Occident chrétien, (Madrid), 51-65.

EWERT, Ch., 1979, Hallazgos islámicos en Balaguer y la Aljaferia de Zaragoza. Madrid.

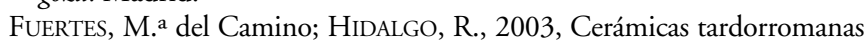
y altomedievales de Córdoba, Cerámicas tardorromanas y altomedievales en la Península Ibérica, Anejos de AEspA XXVIII, (Madrid), 505-540.

GiRAlT, J., 1986, Fortificacions Andalusines a la Marca Superior: el cas de Balaguer Setmana d'Arqueologia Medieval (Lérida), 173-193.

GiRAlt, J., 1994, Jaciment arqueològic del Pla D’Almatà, Catalunya Romànica, XVII (Barcelona), 238-243.

GiRALT, J.; TuSET, T., 1993, Modelos de transformación del mundo urbano en el nordeste peninsular. Siglos V-XIII, IV Congreso de Arqueología Medieval Española, I, (Alicante), 37-46. 
Gómez Moreno, G., 1951, Arte árabe español hasta los almohades. Ars Hispaniae, III. Madrid.

GurriarÁN, P., 2004, Hacia una construcción del poder. Las prácticas edilicias en la periferia andalusí durante el califato, Cuadernos de Madînat al-Zahrâ', 5, 297-325.

GuTiÉRrEZ, S., 1993, De la civitas a la madina: destrucción y formación de la ciudad en el sureste de Al-Andalus, IV Congreso de Arqueología Medieval Española, I (Alicante), 13-35.

GuTiérrez, S., 1998, Ciudades y conquista. El fin de la civitates visigodas y la génesis de las mudun islámicas del sureste de al-Andalus, Genèse de la ville islamique en al-Andalus et au Magreb occidental, (Madrid), 137-157.

GuTiÉRrEZ, S., 2000, Algunas consideraciones sobre la cultura material de las épocas visigoda y emiral en el territorio de Tudmîr, Anejos a AespA, XXIII, 95-116.

GUTIÉRREZ, S., ABAD, L., 2002, Fortificaciones urbanas altomedievales del Tolmo de Minateda (Hellín, Albacete, España): el baluarte occidental, Mil anos de fortificaçôes, (Palmela, Portugal), 133-143.

GuTiérrez, S.; GAmo, B.; Amorós, V., 2003, Los contextos cerámicos altomedievales del Tolmo de Minateda y la cerámica altomedieval en el Sudeste de la Península Ibérica, Cerámicas tardorromanas y altomedievales en la Península Ibérica, Anejos de AEspA XXVIII, (Madrid), $119-168$.

Hernández, F., 1961-2, El codo en la historiografía árabe de la Mezquita Mayor de Córdoba. Contribución al estudio del monumento, Al-Mulk, 2, 5-52.

HernÁndeZ, F., 1979, La alcazaba de Mérida, en K.A.C. Creswell, Early Muslim architecture, II, 197-207.

Hidalgo, R.; Fuertes, M. ${ }^{a}$ del C., 2001, Córdoba, entre la Antigüedad Clásica y el Islam. Las transformaciones de la ciudad a partir de la información de las excavaciones de Cercadilla, Cuadernos Emeritenses, 17, 223-264.

JiménEZ, A., 1979, Compendio de la arquitectura Emiral cordobesa, en Creswell, Compendio de arquitectura paleoislámica. Sevilla. 468-487.

JiméneZ, A., 1989, El Arte Islámico. Historia del Arte, 15. Madrid.

JiméneZ, P., NAvarro, J., 2000, Génesis y evolución urbana de Murcia en la Alta Edad Media, Murcia, ayer y hoy, (Murcia), 40-130.

JimÉNEZ, P., NAVArRo, J., 2001, El urbanismo islámico y su transformación después de la conquista cristiana: el caso de Murcia, La ciudad medieval: de la casa al tejado urbano, (Cuenca), 71-129.

LÉvi-ProvençAL, E, 1938, La Péninsule ibérique au Moyen Age d'après le $<$ Kitâb al-Rawd al-Mi'tar>. Leyde .

LÉZINE, A., 1966, Architecture de l'Ifriqiya. Recherches sur les monuments aghlabides. Paris-Dijon.

MARTínez LiLlo, S., 1991, Estudio sobre ciertos elementos y estructuras de la arquitectura militar andalusí. La continuidad entre Roma y el Islam. Boletín de Arqueología Medieval, 5, 11-37.

MarfiL, P., 1999, Avance de resultados del estudio arqueológico de la fachada este del oratorio de 'Abd al-Rahman en la mezquita de Córdoba, Cuadernos de Madînat al-Zahrâ', 4, 175-207.

Marfil, P., 2000, Córdoba de Teodosio a 'Abd al-Rahman III, Anejos a AespA, XXIII, 117-141.

Mateos, P.; Alba, M., 2000, De Emerita Augusta a Marida, Anejos a AespA, XXIII, 143-168.

MAZZOLI-GUINTARD, CH., 1998, L'urbanisation d'al-Andalus au Ie siècle: données chronologiques, Genèse de la ville islamique en al-Andalus et au Magreb occidental, (Madrid) 99-106.

Murcia, A.J.; Guillermo, M., 2003, Cerámicas tardorromanas y altomedievales procedentes del teatro romano de Cartagena, Cerámicas tardorromanas y altomedievales en la Península Ibérica, Anejos de AEspA XXVIII, (Madrid),169-223.

Murillo, J.F; Casal, M.a T.; Castro, E. 2004, Madînat Qurtuba. Aproximación al proceso de formación de la ciudad emiral y califal a partir de la información arqueológica, Cuadernos de Madînat al-Zahrầ, 5, $257-290$.
Olmo, L., 2000, Ciudad y procesos de transformación social entre los siglos VI y IX: de Recópolis a Racupel, Anejos a AespA, XXIII, 385-399.

PRINGLE, D., 1981, The defense of Byzantine Africa from Justinian to the Arab Conquest. An account of the military history and archaeology of Africa provinces in the sixth and seventh centuries, B.A.R. International Series. Oxford.

Quirós, J.A., 2001, La sillería en la arquitectura altomediveal en el Mediterráneo occidental, $V$ Congreso de Arqueología Medieval Española, (Valladolid), 1, 281-291.

SouTo, J.A., 1983, El conjunto fortificado islámico de Calatayud (Zaragoza). Ensayo de estudio histórico-Arqueológico, (Tesis de licenciatura inédita).

Souto, J.A., 1989, Sobre la génesis de la Calatayud islámica, Aragón en la Edad Media, VIII (Zaragoza), 675-695.

SouTO, J.A., 1990, Ensayo de estudio histórico-arqueológico del conjunto fortificado islámico de Calatayud (Zaragoza): objetivos, metodología y primeros resultados. Anaquel de Estudios Árabes, 1 (Madrid) $187-201$.

SouTO, J.A., 2001, Los constructores de al-Andalus Omeya, El esplendor de los Omeyas cordobeses, I (Córdoba), 274-281.

SouTO, J.A., 2002, La construcción de/en al-Andalus omeya: fortificaciones (y otros elementos) a la luz de varias fuentes escritas, Mil anos de fortificaçôes, (Palmela, Portugal), 77-81.

TABAles RodrígueZ, M.A., 2002, El alcázar islámico de Sevilla, Castillos de España,125 (Madrid), 39-46.

Torres BalBás, L., 1953, La mezquita mayor de Almería, Al-Andalus, 18, 412-430.

TORRES BALBÁS, L., 1957, La Almería islámica, Al-Andalus, XXII, 411-457.

TORRES BALBÁS, L., 1960, Aznalfarache = hisn al-Faray, Al-Andalus, XXV, 222-228.

Torres Balbás, L., 1972, Ciudades hispano-musulmanas. Madrid .

TORRes BALBÁs, L., 1987, Arte Hispanomusulman hasta la caída del califato de Córdoba, en Historia de España. V. España Musulmana, (Madrid), 331-788, 5. a ed.

VV. AA., 1988, Historia General de España y América. Madrid, vol. III.

VV. AA., 1990, La casa hispano-musulmana. Aportaciones de la arqueología. Granada.

VALDÉS, F., 1988, Arqueología de Al-Andalus., de la conquista árabe a la extinción de las primeras Taifas, en Historia General de España y América. III, 545-617.

VAlDÉs, F., 1992, Mayrit. Estudios de arqueología medieval madrileña, Madrid (Editor).

VALDÉS, F., 1992a, El Madrid islámico. Notas para una discusión arqueológica, Mayrit. Estudios de arqueología medieval madrileña, (Madrid), 141-180.

VALDÉs, F., 1995, El aljibe de la Alcazaba de Mérida y la política omeya en el Occidente de Al-Andalus, Extremadura Arqueológica, V, 279-299.

VALDÉs, F., 2001, Acerca de la islamización de Extremadura, Cuadernos Emeritenses, 17, 335-36.

VAlor Piechota, M., 1991, La arquitectura militar y palatina en la Sevilla Musulmana. Sevilla.

VAlor Piechota, M., 1992, La estructura urbana de la Sevilla islámica prealmohade, III Congreso de Arqueología Medieval Española, II, (Oviedo), 327-337.

Viguera, M. ${ }^{\mathrm{a}}$ J.; CASTillo (Eds.), 2001, El esplendor de los Omeyas cordobeses. Córdoba.

ZoZAYA, J., 1984, Islamic fortifications in Spain: some aspects. Papers in Iberian Archaeology B.A.R. International Series, n. ${ }^{\circ}$ 193, (Oxford), 647-648.

ZOZAYA, J., 1988, Evolución de un yacimiento: El castillo de Gormaz (Soria), Castrum 3, 173-178.

ZOZAYA, J., 1990, El Islam en la región madrileña, en Madrid del siglo IX al XI, (Madrid), 195-203.

ZozAyA, J., 1992, Las fortificaciones de Al-Andalus, Al-Andalus. Las Artes Islámicas en España, (Granada) 63-73.

ZOZAYA, J., 2002, Fortificaciones tempranas en al-Andalus, ss. VIII-X, Mil anos de fortificaçôes, (Palmela, Portugal), 45-58. 